\title{
When Foots Come First: Early Signs of Podocyte Injury in Fabry Nephropathy Without Proteinuria
}

\author{
Francesca Becherucci $^{a}$ Paola Romagnani ${ }^{a, b}$ \\ ${ }^{a}$ Nephrology and Dialysis Unit, Meyer Children's Hospital and ${ }^{b}$ Department of Biomedical Experimental and \\ Clinical Sciences 'Mario Serio', University of Florence, Florence, Italy
}

Podocytes are highly specialized epithelial cells that cover the glomerular basement membrane (GBM) with their foot processes, leading to permeselectivity, typical of the glomerular filtration barrier (GFB). As assessed by electron microscopy (EM), proteinuria is associated with striking changes in podocyte architecture and shape, that comprise loss or effacement of the podocyte foot processes and that can represent the solitary hallmark of disease or can be associated to the other abnormalities characteristic of the underlying disease, such as immune deposits or inflammation [1].

Alterations of podocyte architecture and loss of interdigitating foot processes (namely, foot process effacement, FPE) were first described by means of EM in 1950s as the morphological signs accompanying proteinuric diseases, such as minimal change nephrotic syndrome and glomerulonephritis [2].

Subsequently, most proteinuric renal diseases such as diabetic nephropathy and focal segmental glomerulosclerosis have been described as associated with ultrastructural abnormalities compatible with FPE. Furthermore, studies on congenital and familial forms of nephrotic syndrome caused by mutations in genes specifically expressed by podocytes support the hypothesis that podocyte FPE is the primary event that leads to proteinuria $[1,3-6]$.

However, from the late 1970s, both human and experimental models of proteinuric diseases in which podocyte FPE is not present have been reported, as for example

\section{KARGER 125}

() 2015 S. Karger AG, Basel

$1660-8151 / 15 / 1291-0003 \$ 39.50 / 0$

E-Mail karger@karger.com

www.karger.com/nef murine and rat models of vascular endothelial growth factor depletion leading to endotheliosis, alpha- 3 chain of collagen IV knock-out mouse, that represents a murine model of autosomal recessive Alport syndrome, Masugi nephritis model in rats, rare patients with a familial form of nephrotic syndrome in whom podocytes are fully preserved, even in the occurrence of heavy proteinuria, women with preeclampsia, that is histologically characterized by glomerular endotheliosis [7].

The damage to any of the three components of the GFB, that is, endothelial cells, GBM, and podocytes, can eventually lead to the development of proteinuria without necessarily determining the loss or effacement of podocyte foot processes. In addition, studies performed on human biopsies with a variety of diseases showed that FPE is rather dependent on the nature of the underlying disease than on the amount of urinary protein loss. No clear correlation between the degree of podocyte FPE and the entity of proteinuria can be established [1, 4, 8-10], finally suggesting that FPE occurs in many, but not all, proteinuric diseases and that it is not necessary for the development of proteinuria.

Thus, what kind of pathophysiological line links FPE and proteinuria seems to be anything but simple.

Things become even more complicated if one considers that previous studies in animal models have shown that podocyte effacement can be seen in the absence of proteinuria. As an example, rats with puromycin amino- 
nucleoside nephrosis, an experimental model of minimal change disease (MCD), showed FPE few days before the onset of proteinuria $[11,12]$. Similarly, many authors reported patients' foot processes returning progressively to normal after complete remission of the proteinuric phase of MCD $[13,14]$. Interestingly, the full morphologic recovery of foot processes occurs much later than the disappearance of proteinuria, suggesting that mechanisms leading to podocyte cytoskeleton rearrangement and to proteinuria might be different.

All these findings fight against the idea that either in animals or in human abnormal morphology of foot processes cannot exist, at least in some phases of the disease, independently of proteinuria.

In the paper 'Foot processes effacement is an early marker of nephropathy in young classic Fabry patients without albuminuria', Tøndel et al. [15] report the presence of early segmental FPE in children with Fabry disease that showed no clinical signs of renal involvement; in particular, the glomerular filtration rate was normal and proteinuria was not present, neither in male nor in female patients. This discrepancy between early morphologic signs of renal involvement and normal clinical kidney findings has already been described in a few young patients with Fabry disease $[16,17]$.

Nephropathy in Fabry disease is characterized by globotriaosylceramide (GL3) deposition in all glomerular cell types, in particular in podocytes; this process is thought to be age-dependent and only partially affected by enzyme replacement therapy (ERT) [18]. Moreover, GL3 deposits clearance by therapy has not unequivocally been associated with regression or stabilization of Fabry nephropathy, pointing out to mechanisms different than GL3 accumulation alone in the determination and progression of kidney damage [16, 18-20]. From a clinical point of view, Fabry nephropathy is classically recognized as a chronic disease, characterized by the progressive development of proteinuria of increasing severity and by a gradual decline of renal function. Proteinuria may start in children and has for long been considered the first clinical manifestation of Fabry nephropathy. However, ultrastructural morphologic studies on human kidney biopsies have demonstrated that Fabry nephropathy may be prominent even before clinical signs of renal disease become apparent [18].

The results of Tøndel et al. [15] suggest that podocyte FPE could represent a very early sign of kidney injury in Fabry disease, preceding the onset of clinically overt urinary protein loss, as already described for other diseases [21]. As proteinuria is a strong determinant of progres- sion to end-stage renal disease in Fabry disease, these early morphological findings in Fabry nephropathy are likely to be clinically significant.

These data support the hypothesis that FPE represents a response of the podocyte to injury and an attempt to resist to the detachment that could follow an insult [22]. Podocyte injury and loss are the main consequences of glomerular disorders. When podocytes are lost, there is no rapid way except for cell hypertrophy to cover the glomerular tuft and to prevent macromolecules to be leaked in the urine. It is well known, however, that this strategy increases podocyte vulnerability to any additional stress, such as glomerular hypertension $[22,23]$. When exposed to an injurious stimulus, podocytes undergo important changes in shape, which comprise FPE. Notwithstanding this, podocytes do not lose their viability and changes in shape are accompanied by specific ultrastructural rearrangements of cytoskeleton that are hardly interpretable as functionally meaningless. In fact, in vitro and in vivo evidence suggest that podocyte FPE is not a simple pathological derangement of normal podocyte architecture but seems likely to represent a reactive phenotype that may enhance a broad and firm adhesion to the underlying GBM and limit cell detachment and death, at least in the initial phases and in focally distributed glomerular damage [22].

The observations of Tøndel et al. [15] are in agreement with this theory. FPE seems to occur early in the natural history of glomerular damage in Fabry disease, while podocytes depletion develops later. This could eventually represent a common process of disease development in slow and progressive nephropathies [21].

In conclusion, if confirmed in future studies, the assessment of early morphological parameters (such as FPE) in non-proteinuric patients with Fabry disease could help to accurately establish patient's prognosis and to evaluate the more appropriate timing for starting replacement treatment, at least until other noninvasive biomarkers would become available in clinical daily practice.

References

Becherucci/Romagnani

\footnotetext{
van den Berg JG, van den Bergh Weerman MA, Assmann KJ, Weening JJ, Florquin S: Podocyte foot process effacement is not correlated with the level of proteinuria in human glomerulopathies. Kidney Int 2004;66:19011906.

$>$ Farquhar MG, Vernier RL, Good RA: An electron microscope study of the glomerulus in nephrosis, glomerulonephritis, and lupus erythematosus. J Exp Med 1957;106:649660.
} 
3 Mundel P, Shankland SJ: Podocyte biology and response to injury. J Am Soc Nephrol 2002;13:3005-3015.

4 Deegens JK, Dijkman HB, Borm GF, Steenbergen EJ, van den Berg JG, Weening JJ, Wetzels JF: Podocyte foot process effacement as a diagnostic tool in focal segmental glomerulosclerosis. Kidney Int 2008;74:1568-1576.

5 Gundersen HJ, Seefeldt T, Osterby R: Glomerular epithelial foot processes in normal man and rats. Distribution of true width and its intra- and inter-individual variation. Cell Tissue Res 1980;205:147-155.

-6 Bjørn SF, Bangstad HJ, Hanssen KF, Nyberg G, Walker JD, Viberti GC, Osterby R: Glomerular epithelial foot processes and filtration slits in IDDM patients. Diabetologia 1995;38:1197-1204.

7 Kalluri R: Proteinuria with and without renal glomerular podocyte effacement. Am J Kidney Dis 2004;43:933-938.

8 Shankland SJ: The podocyte's response to injury: role in proteinuria and glomerulosclerosis. Kidney Int 2006;69:2131-2147.

-9 Dijkman HB, Gerlofs-Nijland ME, van der Laak JA, Wetzels JF, Groenen PJ, Assmann KJ: Podocyte changes after induction of acute albuminuria in mice by anti-aminopeptidase A mAb. Nephron Exp Nephrol 2003;94:e85e93.
10 Seefeldt T, Bohman SO, Jørgen H, Gundersen HJ, Maunsbach AB, Petersen VP, Olsen S: Quantitative relationship between glomerular foot process width and proteinuria in glomerulonephritis. Lab Invest 1981;44:541-546.

11 Harkin JC, Recant L: Pathogenesis of experimental nephrosis electron microscopic observations. Am J Pathol 1960;36:303-329.

12 Ericsson JL, Andres GA: Electron-microscopic studies on the development of the glomerular lesions in aminonucleoside nephrosis. Am J Pathol 1961;39:643-663.

13 Folli G, Pollak VE, Reid RT, Pirani CL, Kark RM: Electron microscopic studies of reversible glomerular lesions in the adult nephrotic syndrome. Ann Intern Med 1958;49:775-795.

14 Liu XJ, Zhang YM, Wang SX, Liu G: Ultrastructural changes of podocyte foot processes during the remission phase of minimal change disease of human kidney. Nephrology (Carlton) 2014;19:392-397.

15 Tøndel C, Kanai T, Larsen KK, Ito S, Politei JM, Warnock DG, Svarstad E: Foot process effacement is an early marker of nephropathy in young classic Fabry patients without albuminuria. Nephron 2015;129:16-21.

16 Tøndel C, Bostad L, Larsen KK, Hirth A, Vikse BE, Houge G, Svarstad E: Agalsidase benefits renal histology in young patients with Fabry disease. J Am Soc Nephrol 2013;24: 137-148.

17 Kanai T, Yamagata T, Ito T, Odaka J, Saito T, Aoyagi J, Kobayashi M, Ohashi T, Ueda Y, Momoi MY: Foot process effacement with normal urinalysis in classic fabry disease. JIMD Rep 2011;1:39-42.
18 Najafian B, Svarstad E, Bostad L, Gubler MC, Tøndel C, Whitley C, Mauer M: Progressive podocyte injury and globotriaosylceramide (GL-3) accumulation in young patients with Fabry disease. Kidney Int 2011;79:663-670.

19 Germain DP, Waldek S, Banikazemi M, Bushinsky DA, Charrow J, Desnick RJ, Lee P, Loew T, Vedder AC, Abichandani R, Wilcox WR, Guffon N: Sustained, long-term renal stabilization after 54 months of agalsidase beta therapy in patients with Fabry disease. J Am Soc Nephrol 2007;18:1547-1557.

20 Eng CM, Fletcher J, Wilcox WR, Waldek S, Scott CR, Sillence DO, Breunig F, Charrow J, Germain DP, Nicholls K, Banikazemi M: Fabry disease: baseline medical characteristics of a cohort of 1765 males and females in the Fabry Registry. J Inherit Metab Dis 2007;30:184192

21 Torbjörnsdotter TB, Perrin NE, Jaremko GA, Berg UB: Widening of foot processes in normoalbuminuric adolescents with type 1 diabetes. Pediatr Nephrol 2005;20:750-758.

22 Kriz W, Shirato I, Nagata M, LeHir M, Lemley $\mathrm{KV}$ : The podocyte's response to stress: the enigma of foot process effacement. Am J Physiol Renal Physiol 2013;304:F333-F347.

23 Lasagni L, Lazzeri E, Shankland SJ, Anders HJ, Romagnani P: Podocyte Mitosis - a catastrophe. Curr Mol Med 2013;13:13-23. 